\title{
ANALYSIS AND OPTIMIZATION OF HORIZONTAL AXIS WIND TURBINE BLADE PROFILE
}

\author{
Rohan Kapdi $^{1}$, Rahul Dahiya ${ }^{2}$, Vishal Gangadhar Naranje ${ }^{3}$ \\ ${ }^{1}$ Student, Mechanical Engineering Department, BITS PILANI, Dubai, U.A.E \\ ${ }^{2}$ Student, Mechanical Engineering Department, BITS PILANI, Dubai, U.A.E \\ ${ }^{3}$ Professor, Mechanical Engineering Department, BITS PILANI, Dubai, U.A.E
}

\begin{abstract}
With new emerging technologies and innovations in energy sector future seems to be bright. But there's still few years for implementation of those technologies in commercial market. In time there is need to optimize existing technologies and increase their efficiency. Present research is one step towards that goal. This paper analyses and determine the optimum angle of attack at specific wind velocity for horizontal axis wind turbine. Analysis is done by setting wind speed to $10 \mathrm{~m} / \mathrm{s}$ (as this is average wind speed in most open area where wind turbines are placed) and by changing the angle of attack (6, 7, 8, 9 degrees) variation in different properties such as the power output, pressure distribution is determined. Pressure distributions as well as coefficient of lift to coefficient of drag ratio of different the airfoils are visualized and compared. Finite element analysis (FEA) and computational fluid dynamics (CFD) tools are used for analysis of wind turbine. The paper also discusses important parameters in design of wind turbine blade to maximize the efficiency. From the analysis and design optimization of wind turbine blade, it is found out that, at velocity of $10 \mathrm{~m} / \mathrm{s}$, blade with angle of attack of 8 degree is optimum for harvesting power from wind. Thus, only optimizing blade angle of attack increases power, changing other parameters like material type,
\end{abstract}

Keywords: Wind turbine blade, Angle of attack, Finite element analysis (FEA), Computational fluid dynamics (CFD). $* * *$

\section{INTRODUCTION}

Demand for energy all over the world is increasing day by day. There is no hope for its decrement, this is because population will keep on increasing and thus the demand. In such increasing demand, it's very hard to meet all the demand and if met will lead to environmental pollution and other negative consequences on the environment, as most of today's energy is generated by through non-renewable energy sources. According to Ministry of Wind energy, 3\%$5 \%$ of world's energy is generated using wind turbine. Wind turbines generate electricity using wind through its blades. Thus it's sustainable and depends mainly on velocity of wind across the blades. We know that our traditional fuel resources are limited which is getting short day by day. In this condition wind power can be a very suitable replacement for power production. In this paper the wind turbine blades are design in with aim to increase the efficiency of turbine. Also discusses the various ways to optimization the wind blade design process. Thus this paper is one step forward for increasing efficiency of already designed wind turbine blades. This combined with smart electrical systems will lead to less wastage of power and more power generation.

\section{LITERATURE REVIEW}

Over the years, wind turbine blades has gone through many phases of development, researchers are still trying to improve the performance of the wind turbine. In this section a review is carried out on work done by various researches in the area of performance improvement of the wind turbine blade and its optimization. Saxena and Agrawal [1] analyzed a basic aerodynamic theory of wings and the provided and methodology for wind tunnel testing. They found angle of attack at which the lift is maximized in order to get the best performance of this wing when in flight. Mokhtar and Setiawan [2] developed an experimental setup to perform aerodynamic simulations around HAWT blades and designing of small wind turbine blades. McCosker [3] designed a wind turbine using NACA 4412 profile for residential use. Óskarsdóttir [4] gives a general account and evaluation of (HAWT) horizontal axis wind turbines and (VAWT) vertical axis wind turbines. Baldacchino [5] determined the existence of the earth and exterior distresses, most particularly, alterations in wake pitch and the rotor thrust coefficient. Sherry et. Al [6] studied the vortex interface and steadiness of the helical whirlpool strands within a (HAWT) horizontal axis wind turbine wake. Serhat Duran [7] studied HAWT blade design from the aspect of aerodynamic view and the basic principles of the aerodynamic behaviors of HAWTs. DeCoste et al. [8] designed a vertical axis wind turbine using NACA 0012 aero foil structure. MATLAB software is used to obtain lift and drag coefficients, angles of attack and relative wind speeds. Herbert et al. [9] discussed the design procedure and outcomes of the sandia 34.1-m VAWT Test Bed platform and the FloWind prototype development platform with asense toward future offshore designs. Castillo [10] designed a small (VAWT) vertical axis wind turbine rotor with the hard timber as a building material. The smooth analysis was performed employing a thrust based model on a scientific main frame program. Deisadzeet al. [11] studied 
the potential for installing roof-mounted vertical axis wind turbine (VAWT) systems on house roofs. Yu-MIng et al [12] performed analysis based on structure first approach which proposed the constraint expressions of blade which have fine structure. Narimahet al. [13] carried out analysis using Autodesk Inventor to develop three dimensional model of NACA 4412 airfoil blades with and without slot before assessment of smooth features by using ANSYS software. Manyonge et al. [14] made a mathematical model of wind turbine to understand the behaviour of the wind turbine over its region of operation. According to Bergey [15], Griffiths, the maximum conversion efficiency of the horizontal axis wind turbine (HAWT) is $16 / 27$. Air is treated stationery, non-viscous and incompressible in the flow analysis. Unique main significance of wind turbine design is its number of blades. Number of blades is significantly prompting, the horizontal axis wind turbines (HAWT). Most common number used are 2 and 3 blades. Nearly some HAWTs might have more than 3 blades, and usually because they are used for low speed wind turbines and most of the current viable turbines used for power generation have three blades. It is well-known that additional blades offer a larger available surface area for the wind to push, so it would yield additional rotating power but in the similar period a larger number of blades upsurge the weight to be rotated by the turbine. Bottasso [16] described a method for the structural optimization of wind turbine rotor blades for given prescribed aerodynamic shape. The study of Snel [17] gives overview of different methods, to evaluate the aerodynamic performance of wind turbine. Hosman made a performance analysis and improvement of small wind turbine. Abottanalyzed the properties of airfoil using 32 theory of airfoil section. According to Grifith, the output power of the turbine depends on lift/drag ratio. Hassanien et al. stated that the selection of airfoil should be so that location along the blade ensures highest contribution to the overall performance. Sepera studied the Wilson's methods of blade design. The main objective of the revision is to improve the power coefficient of wind turbine using appropriate blade design at rated wind speed. Maalawi et al. studied the theoretical optimum distribution of the inflow angle using trigonometric function methods which are based on ideal condition. Thumthae and Chitsomboon presented the arithmetical simulation of (HAWT) horizontal axis wind turbines with uncoiled edge in the steady state condition. The objective was to investigate the situation for the optimum pitch that yields the maximum power production. Stoceves and Peinke [18] discussed the variations in the wind speediness and wind course from a statelygale field and were examined at higher rates. This was used towards eliminating the angle of attack over blade section which were occurring over small time intervals. Kumar et al conducted an experiment using NACA 4420 airfoil from $0^{\circ}$ to $12^{\circ}$ of attack using CFD. They concluded that 50 of attack resulted high lift/drag ratio. Sheldahlet al [19] of Sandia National Laboratories investigated the performance of NACA 0009 and NACA 0012 airfoils for different angles of attack. Angle of attack is varied from $0^{\circ}$ to $180^{\circ}$. They concluded that $45^{\circ}$ of attack yields maximum lift coefficient.

\section{AIRFOIL DESIGN}

An airfoil means a two dimensional cross-section shape of a wing whose purpose is to either generate lift or minimize drag when exposed to a moving fluid [20].

\subsection{Airfoil Design Procedure}

1. Select the diameter of rotor required for the purpose. Size of rotor id important for determining power output, shown in equation below:

$$
P=C_{P} \eta\left(\frac{1}{2}\right) \rho \pi R^{2} V^{3}
$$

Where; $V$ is the expected wind velocity, $\mathrm{P}$ is the power output; $C p$ is the expected coefficient of performance (is around 0.4 for a modern three bladed wind turbine); $\eta$ is the mechanical efficiencies ( 0.9 would be an appropriate value); $R$ is the tip radius.

2. Lambda value depends on the type of application. For example for, electrical power generation, consider $4<\lambda<10$.

3. Determine and choose number of blades from the Table 1.

Table 1: Tip speed ratio Vs Number of Blades

\begin{tabular}{|l|l|}
\hline$\lambda$ (tip speed ratio) & $\mathrm{B}$ \\
\hline 1 & $8-24$ \\
\hline 2 & $6-12$ \\
\hline 3 & $3-6$ \\
\hline 4 & $3-4$ \\
\hline$>4$ & $1-3$ \\
\hline
\end{tabular}

4. Select a airfoil based on the lambda value. If $\lambda<3$, curved plates can be selected and used. And if $\lambda>=3$, a more aerodynamic shape has to designed and used.

Obtain and examine lift and drag coefficient curves for the selected airfoil. Note that different airfoils may be used at different spans of the blade; a thick airfoil may Table-1: $\lambda$ and Number of Blades be selected for the hub to provide a greater strength.

5. Choose the plan aerodynamic situation for separate airfoil. Characteristically choose $80 \%$ of the extreme lift value, these prime efficiently fixes the blade twist. On elongated edges a very huge grade of twist is vital to attain $80 \%$ of the concentrated lift nearby the hub. These is not essentially wanted as the hub cropslone a minor quantity of the power production, a settlement is to admit that the airfoils will take outsized angles of attack at the hub.

6. There is no easy physically accessible way of choosing chord distribution of air foil. A simplification of an ideal blade is given by

$$
C=\frac{8 \pi \mathrm{r} \cos \beta}{3 \mathrm{~B} \lambda r}
$$


This gives moderately linear distribution and complex shape for the chord, which is easy for Ansys to solve.

7. Divide the blade into 10-20 elements. Typical number of element division is around 15. "N" stands for number of elements.

8. For the flow solution use the following equations..This equations are derived from design of blade profile with zero drag and zero tip speed ratio using wake solution. This equations only provide initial gas.

The equations are given as:

$a=\left(1+\frac{4 \cos ^{2} \beta}{\sigma^{\prime} C_{L} \sin \beta}\right)$

$$
\beta=90^{\circ}-\frac{2}{3} \tan ^{-1}\left(\frac{1}{\lambda r}\right)
$$

\section{DESIGN PARAMETERS}

Following are the design parameters are consider for design of wind turbine blades:

I. Thickness of Airfoil

II. Design of Upper and Lower Surface

III. Lift and Drag Force

The airfoil thickness is determine using following equation

$$
\begin{gathered}
\pm y=\left(\frac{t}{0.2}\right) *\left(0.2969 * x^{0.5}-0.126 * x-0.3537 * x^{2}\right. \\
\left.+0.2843 * x^{3}-0.1015 * x^{4}\right)
\end{gathered}
$$

Where;

$\mathrm{x}=$ is coordinates along the length of the airfoil, from 0 to $\mathrm{c}$, where is " $c$ " is the length.

$\mathrm{y}=$ thickness distribution, these are also written as $y_{t}$ for thickness coordinates

$\mathrm{t}=$ is the maximum airfoil thickness in $1 / 10$ of chord (i.e. a $15 \%$ thick airfoil design would be around 0.15 )

Another important parameter is design of upper and lower surface wind turbine blade is calculated by using following expression

$$
\begin{gathered}
Y_{C}=\frac{m}{p^{2}}\left(2 p x-x^{2}\right) ; x \leq x_{y c \max } \\
\left.Y_{C}=\frac{m}{(1-p)^{2}}[(1-2 p)]+2 p x-x^{2}\right] ; x>x_{y c \max }
\end{gathered}
$$

$Y_{C}=$ Camber

$\mathrm{m}=$ maximum ordinate position of camber line as fraction of the chord.

$\mathrm{p}=$ chord wise position of the maximum camber as fraction of the chord.

Lift and drag force on wind turbine are calculated using following expression

$$
F_{D}=\int D F_{D}=-\int(P \cos \theta+\tau \sin \theta) d A
$$

And he lift force is,

$$
F_{L}=\int D F_{L}=-\int(P \sin \theta+\tau \cos \theta) d A
$$

Drag force and lift force can also be written by using coefficient of drag and co-efficient of lift respectively.

$$
F_{D}=\frac{1}{2} \rho A V^{2} C_{D} \quad F_{L}=\frac{1}{2} \rho A V^{2} C_{L}
$$

Where; CD and CL are coefficient of lift and coefficient of drag. $\rho$ is density of air, which is constant.

Table 2: Details of selecting of angle of attack

\begin{tabular}{|l|l|l|}
\hline $\begin{array}{l}\text { Angle of } \\
\text { Attack }(\alpha)\end{array}$ & Lift Coeff. $\left(\mathrm{C}_{\mathrm{L}}\right)$ & Drag Coeff. $\left(\mathrm{C}_{\mathrm{D}}\right)$ \\
\hline 0 & 0.475 & 0.007 \\
\hline 8 & 1.305 & 0.012 \\
\hline 9 & 1.373 & 0.015 \\
\hline 10 & 1.433 & 0.017 \\
\hline 11 & 1.491 & 0.0196 \\
\hline 12 & 1.541 & 0.0243 \\
\hline
\end{tabular}

\section{MODELLING OF AIRFOIL}

CATIA software is used to model the complex blade geometry. Co-ordinates of wind turbine blade were transferred to CATIA from CATIA genrativedig. After transferring blade model, it was modified and to values shown in table 3 , chord length $0.4 \mathrm{~m}$ and length of blade as $2.75 \mathrm{~m}$ on 1:5 scale [21]. Trailing edge stiffener is added at the end of blade, to avoid crimping and sticking of blades during simulation. Figure 2 shows a sketch of the blade section and virtual wind tunnel. Aero dynamicity [22] of blade is maintained during this modelling process.

Table 3: Parameters of wind turbine blade

\begin{tabular}{|l|l|}
\hline Parameters & Specifications \\
\hline Number of blades & 3 \\
\hline Blade material & Steel/alloy \\
\hline Chord length & 0.4 \\
\hline Length of blade & $2.75 \mathrm{~m}$ \\
\hline Angle of attack & $6,7,8,9$ \\
\hline Scale & $1: 5$ \\
\hline
\end{tabular}

\section{COMPUTATIONAL FLUID DYNAMICS (CFD) OF WIND TURBINE BLADE}

\subsection{Meshing and Boundary Layer Conditions}

Meshing of blade is carried out using tetrahedral mesh using Ansys ICEM software. 


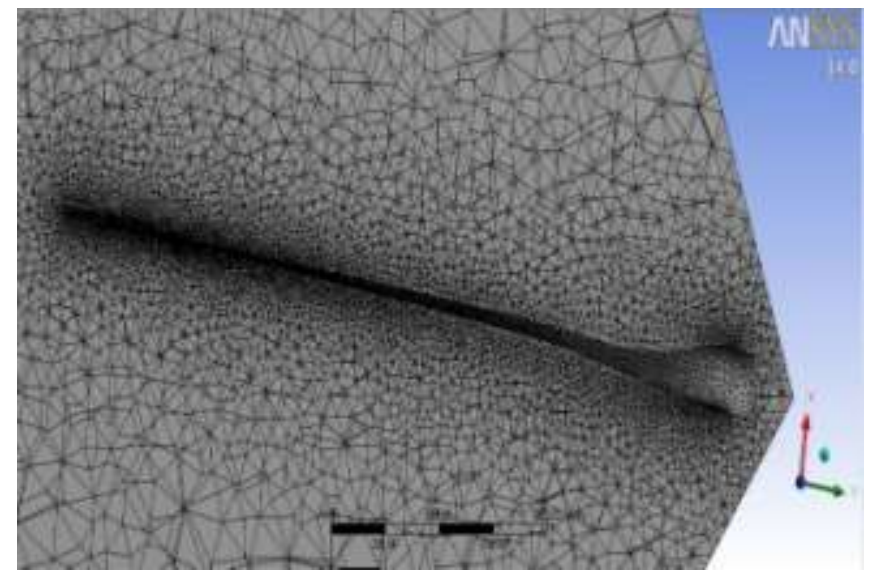

Fig 1.Blade meshing and fluid meshing separately

In this Blade has been transferred into Ansys 14.5 using coordinates from MS-Excel. Meshing of blade has been done using tetrahedral mesh using Ansys ICEM software. Mesh consist of 8778 Nodes and 4691 elements with no mesh matric. Inflation ratio is set to 0.272 with growth rate of 1.2. Mesh is smooth in nature with transition as fast and Spane angle course. Mesh is very precise and small near the contact surface of both surfaces, this has been done because surface contact is our main area of focus to get precise results.

\subsection{Virtual Wind Tunnel}

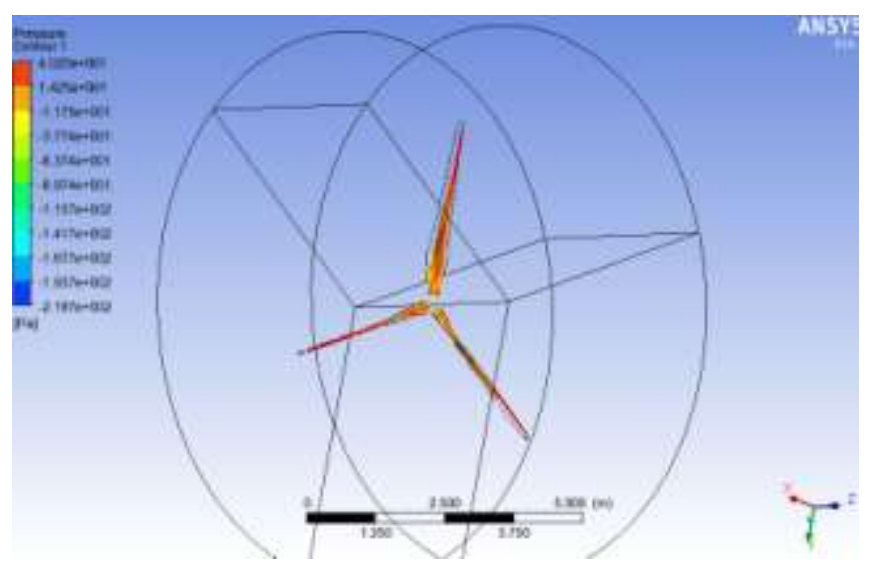

Fig. 2 Wind Tunnel

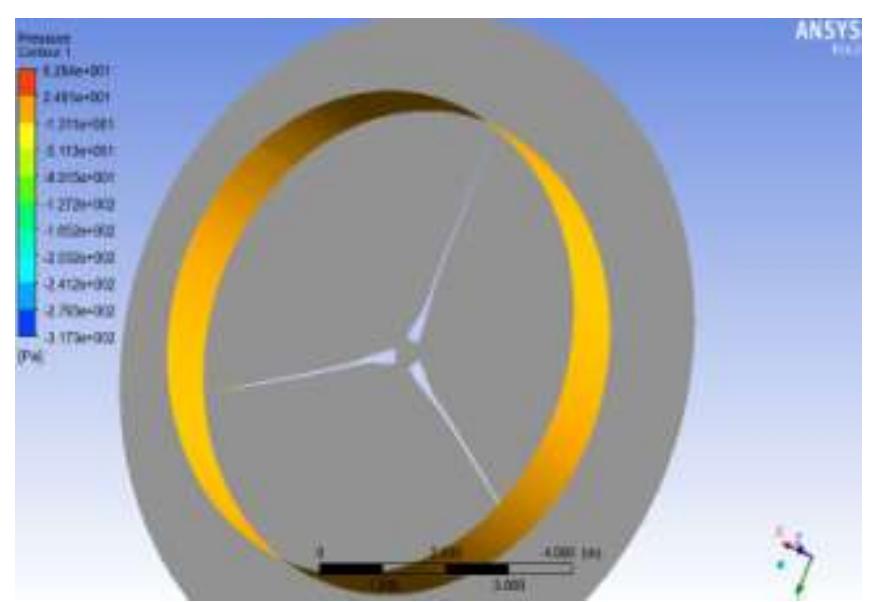

Fig. 3 HAWT Plane
Simulation on wind turbine blade was carried out by constructing virtual wind tunnel. Boundary conditions were set by referring into different journals. In the above image tunnel is 3 times the size of blade. Rotor of blade is discarded because it was very difficult to mesh it. Fig 2. And Fig 3. Represents virtual wind tunnel constructed for analysis purpose in CFD.

\subsection{Boundary Layer Conditions}

\subsubsection{Inlet Conditions (Velocity Inlet)}

Inlet condition for any system has to be precisely selected and added. In this case velocity of wind is inlet condition for virtual wind tunnel. Direction of wind striking the tunnel is perpendicular to its surface. Turbulence is main factor that affects the efficiency of the system. Inlet turbulence intensity is set to $0.5 \%$ and viscosity of $1.78 \mathrm{e}-05$ for air flowing through the blade of wind turbine.

\subsubsection{Outlet Conditions (Pressure Outlet)}

Outlet condition is equally important to inlet conditions. This is because, behavior of air within the system depends on outlet condition. Outlet condition is set as pressure based. Pressure of air leaving is considered as atmospheric pressure.

\subsubsection{No Slip Wall}

No slip condition is important condition in setting practical behavior of system. This accounts the friction between the wall and air molecules. Setting this condition ON, assumes velocity of air near on the blade near to zero..3.

\subsubsection{Periodic}

Rotation of wind turbine is periodic in nature, i.e after certain rotations and time, conditions and output repeats itself. To account for this periodicity, periodic option is considered. This significantly reduces time of calculation without compromising with precision, and also reduces domain size. In this simulation as three bladed turbine is considered computational domain is taken 120 degree.

\subsubsection{Symmetry}

Summary of the boundary conditions is shown in Table 4:

Table 4: Boundary conditions details

\begin{tabular}{|l|l|}
\hline Wind turbine components & BC type \\
\hline Blade & No-slip Wall \\
\hline Far-field & Symmetry \\
\hline Inlet & Velocity-inlet \\
\hline Periodic faces & Periodic \\
\hline Outlet & Pressure- Outlet \\
\hline Half Cylinder & Symmetry \\
\hline Material & Aluminium \\
\hline Wind Speed & $10 \mathrm{~m} / \mathrm{s}$ \\
\hline
\end{tabular}




\section{RESULTS}

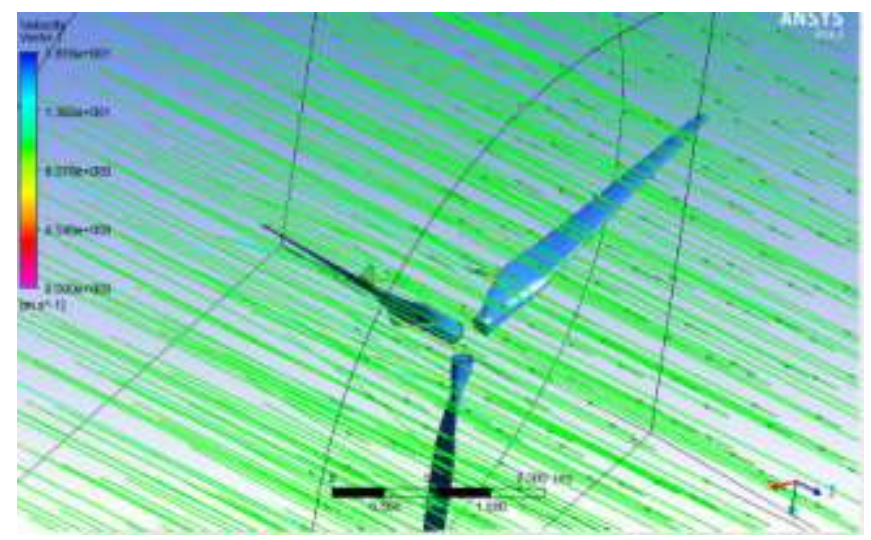

Fig. 5Velocity Countor line at AoA: 8

Fig 3 represents velocity vector lines at $10 \mathrm{~m} / \mathrm{s}$. We can see that variation in velocity of wind is very low at 8 angle of attack.

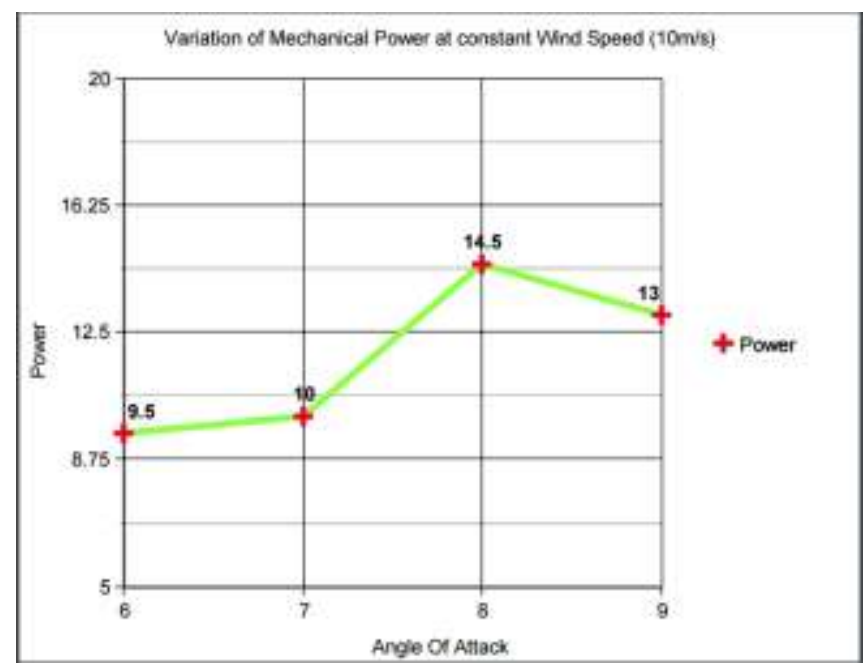

Fig 7 Graphical representation of angle of attack Vs power generated

From the above graph (Fig 7.) it can be seen that power generated by wind turbine increases with increase in angle of attack. And reaches the optimum at angle of attack 8 degrees. Mechanical power is increased dramatically while angle of attack changes from 6 to 8 degreewhen the angle of attack is 8 degrees, power is maximum, the theoretical mechanical power is $14.56 \mathrm{~kW}$ at A.o.A $=8$ power output is maximum i.e. above $14.56 \mathrm{KW}$. So, From above graphical results we found out the optimum A.o.A and wind velocity,A.o. $\mathrm{A}=8$ degrees, $\mathrm{v}=10 \mathrm{~m} / \mathrm{s}$ at this parameters maximum power generated is between $14.56-16 \mathrm{KW}$. So, by changing the combination of parameters like A.o.A, rotational speed of wind turbine, wind speed, optimum amount of power can be generated. This implies that, different combinations may exist for same output.

\section{CONCLUSION}

Thus, NACA 4412 profile was analyzed for maximum power output. Final fluid analysis shows the maximum power output at 8 degree angle of attack (at constant wind velocity of $10 \mathrm{~m} / \mathrm{s}$ ). Also, the use of NACA 4412 has very well aerodynamically performance and low Reynolds numbers. Finally it can be concluded that with increase inangle of attack, efficiency of wind turbine increases till angle of attack 8 degrees and then decreases.

\section{ACKNOWLEDGEMENT}

I would like to thank Dr. Vishal for guiding me throughout the research and for his valuable advice.

\section{REFERENCES}

[1] Baldacchino D and van Bussel G, 2014, "Wind turbine wake stability investigations using a vortex ring modelling approach", Journal of Physics: Conference Series 555012111.

[2] Medjroubia, W et al., 2011, "High-order Numerical Simulations of the flow around a heaving Airfoil" Computers and Fluids, Vol. 51, pp. 68 -84.

[3] Sheldahl et al. (1981) "Wind Tunnel Performance forDarieuss" In Sandia Energy.

[4] Manyonge A W et al., 2012, "Mathematical Modelling Of Wind Turbine In a Wind Energy Conversion System-Power Coefficient Analysis" Applied Mathematical Sciences, 6, pp. 4527-4533

[5] Bottasso C L ET. 2014. Al "Structural Optimization of Wind Turbine Rotor Blades by Multi-Level Sectional/Multibody/3DFEM Analysis". Multibody System Dynamics. Vol 32, pp 87-11

[6] Castillo, 2011, "Small Scale Vertical Axis Wind Turbine Design"- Bachelor's Thesis, Tampere University of Applied Science.

[7] DeCoste et al., 2005, "Starting Torque Study of Darrieus Wind Turbine"- World Academy of Science, Engineering and Technology International Journal of Mathematical, Computational, Physical, Electrical and Computer Engineering Vol:9, 2015

[8] Deisadze et al., 2013, "Vertical Axis Wind turbine Evaluation and Design" Bachelor's Thesis, Worcester Polytechnic Institute.

[9] Duran S, 2012, "CAD design of horizontal axis wind turbine", Renewable Energy, 44, pp. 252-260

[10] G. ming, Y. Fei, Z. Jing, X. Yan-jun, 2010, "Design of Wind Turbine Blade based on Structure-First Approach" Information Engineering (ICIE), WASE International Conference, Vol 3, pp. 148-151

[11] Griffiths, R T, 1977, the effect of airfoil characteristics on windmill performance. Aeronautical J. 81, pp.322326.

[12] Hassanein, A., El-Banna, H. \& Abdel-Rahman, M. (2000) Effectiveness of airfoil aerodynamic characteristics on wind turbine design performance. Proc. Seventh International Conference on Energy and Environment, vol. I. Cairo, Egypt, March 2000, 525 537.

[13] Herbert J. Sutherland and Paul S. Veers. 1995 "Effects of Cyclic Stress Distribution Models on Fatigue Life Predictions", Wind Energy-, SED-Vol. 16, ASME, pp. 83-90. 
[14] Hsiao F B, Bai C J, Chong W T, 2013, "The performance test of three different horizontal axis wind turbine (hawt) blade shapes using experimental and numerical methods energies, 6, pp. 2784-2803

[15] kumar et al., 2010, "Renewable energy in India: current status and future potentials", Renewable \& Sustainable Energy Reviews, Vol. 14, pp. 2434-2442

[16] McCosker J, 2012, "Design and optimization of a small wind turbine", Rensselaer Polytechnic Institute Hartford, Connecticut, 3, pp.456-495.

[17] Narimah et al., 2014, "Performance Evaluation of slotted and Continuous Types Wind Turbine Blades" Master's Thesis, University Tun Hussein onn, Malaysia.

[18] Oskarsdottir M, 2014, "A general description and comparison of horizontal axis wind turbines and vertical axis wind turbines", faculty of industrial engineering, mechanical engineering and computer science school of engineering and natural sciences university of icelandreykjavik,

[19] Paor (1982), Aerodynamic Design of Optimum Wind Turbines, Applied energy vol.12, pp. 221-228

[20] Saxena G. and Agrawal M, 2013, "Aerodynamic analysis of NACA 4412 airfoil using CFD", International Journal of Emerging Trends in Engineering and Development,4, pp.416-423.

[21] Sherry M, Sheridan J, Lo Jacono D, 2013, "Characterisation of a horizontal axis wind turbine's tip and root vortices", Experiments Fluids 54, 1417

[22] Snel et al. ,2003, "Review of Aerodynamics for Wind Turbines",Wind Energy Journal,vol 6, pp. 203-211

\section{BIOGRAPHIES}

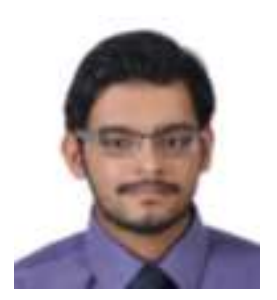

Rohan shanker Kapdi: Undergraduate fourth year mechanical engineering student at BITS PILANI, DUBAI. He enjoys watching TV shows and playing outdoor games like cricket and rugby.

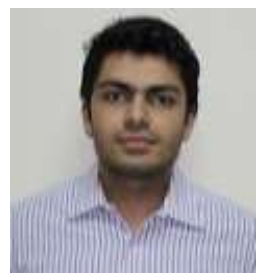

Rahul Dahiya: Undergraduate fourth year mechanical engineering student at BITS PILANI, DUBAI. He is motivated towards solving energy issues faced by world today. Have sound knowledge of computational fluid dynamics, nuclear physics. Has completed projects related analysis of carbon nanotube reinforced airplane wing. As leisure activities he enjoys outdoor sports like football, swimming and music.

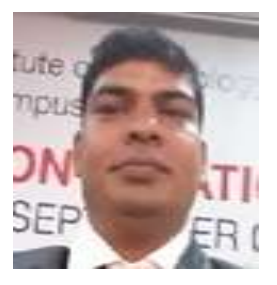

Dr. Vishal Gangadhar Naranje: Mechanical engineering professor at BITS PILANI, DUBAI. He earned his Ph.D in Department of Mechanical Engineering, He has dedicated his life in enriching lives of students with his knowledge and experience. 